\title{
Integrated Green Supply Chain Model to Reduce Carbon Emission with Permissible Delay-in-Payment Consideration
}

\author{
Muhammad Faisal Ibrahim *, Maulin Masyito Putri \\ Logistic Engineering, International University Semen Indonesia, Indonesia \\ Jl. Veteran Gresik, Jawa Timur, Indonesia \\ * Corresponding author: faisalibrahim.ie@gmail.com
}

\section{ARTICLE INFO}

Article history

Received May 26, 2019

Revised July 11, 2019

Accepted July 24, 2019

Available Online August 31, 2019

Keywords

Supply Chain Management

Green Supply Chain

Permissible Delay in Payment

Carbon Emission

\begin{abstract}
In practice, the policy of delaying payment periods is prevalent between players in a supply chain system. Generally, payments are made at the end of the permitted period. Supply chain management is one of the keys to corporate sustainability that the activities impact the environment. This paper aims to develop an integrated green supply chain model with a permissible delay in payment consideration. In this research, the author develops a mathematical model to find the effect of delay in payment on emissions costs without ignoring the economic performance of a supply chain. The author develops four different scenario models. Furthermore, numerical experiments and sensitivity analysis tests were conducted. The study results show that delay in payment is integrated into the supply chain system, which has a positive impact on reducing supply chain emissions costs.
\end{abstract}

This is an open-access article under the CC-BY-SA license.

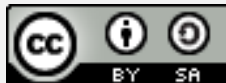

\section{Introduction}

The environmental effect of carbon emission is often ignored in manufacturer and transportation activity. King and Lenox [1] Claimed that unplanned and irresponsible actions by industries are potential threats to sustainability. Companies are now trying to minimize environmental impacts by integrating environmental concerns into their supply chain operations [2]. Several previous studies discussed the approaches to reducing carbon emissions. Zissis, et al. [3] and Peng, et al. [4] used a quantity discount as a medium in coordinating the supply chain to reduce carbon emission. Besides, revenue [5-7] and investment sharing [8] in the supply chain can reduce carbon emissions. Supply Chain Management (SCM) becomes one of the centers of attention in a company with corporate sustainability. The supply chain is a very complex topic when it involves many functional areas inside and outside the company for improving company performance [9]. Besides, the supply chain is running to minimize costs. Aljazzar, et al. [10] explained that the order cost, storage cost, and setup cost are essential components in the supply chain costs. Waters [11] stated that these costs in the supply chain continue to increase. Inventory in 
the supply chain must be well maintained to ensure the sustainability of the company. The efficient supply chain can occur with reasonable cooperation and coordination [12-17].

Some previous studies proved that coordinating the supply chain could minimize the cost [18-20]. With coordination in SCM, buyers and sellers can get the benefit. A good coordination scheme can coordinate sellers and buyers more flexibly [18]. According to Sainathan and Groenevelt [19], several types of contracts can coordinate supply chains, including quantity discounts, buyback, and revenue sharing. In the other studies, delay in payment contracts also successfully organized several players in the supply chain system [21]. Supply chain management always pays attention to improve company performance and maintain organizational sustainability [22]. The increase of global warming and changing biodiversity has brought the world's sustainability towards immediate danger. Researchers, academicians, practitioners, and scientists together suggest ways to maintain the environmental sustainability. King and Lenox [23] Claim that unplanned and irresponsible actions by industry are a threat to sustainability. Companies now attempt to minimize the environmental impact by integrating environmental issues into their supply chain operations. According to Sarkis and Dou [24], the integration of supply chain elements with corporate environmental management that referred to as "Green Supply Chain." According to Jaber and Osman [25] and Ibrahim [26], delay in payment is a policy to coordinate players in the supply chain by allowing the customer to delay payments for a specified period without interest. Delay in payment is also used as a strategy to increase sales and reduce inventory in the warehouse. Several previous studies have proven that the policy positively impacts companies [9, 14, 15, 21, 25, 27, 28]. When the delay in payment is applied in a supply chain system, total supply chain costs can decrease [9].

Based on previous research, delay in payment policy have been studied. However, far too little attention has been paid to integrating the green supply chain model with permissible delay in payment considering carbon emission. This paper aims to develop an integrated green supply chain model with permissible delay in payment considering carbon emission. The contribution of this paper is the integration of the two-echelon supply chain model with delays in payments to minimize emissions costs. In this paper, the author developed four different case scenarios under permissible delay in payment. The research result shows that delay in payment mechanisms successfully reduced carbon emission. It is proven by emission costs that are more compared minimally when no delay in payment mechanism. This paper also provides some insights for managerial practitioners. In this research, mathematical models were developed into four case scenarios, according to a recent study by Ibrahim [21]. Some variables were added with consideration of carbon emission. The numerical experiment was conducted with several different case scenarios. Sensitivity analysis is carrying out several variables that are considered significant to the total change of supply chain system cost. The organizing of this paper as follows: Section 2 is for presenting the notation, assumption, conceptual model, and mathematical model. Section 3 is for results and discussion, including numerical examples. Moreover, section 4 shows the conclusion.

\section{Methods}

In this section, the mathematical model was developed based on the conceptual model and several assumptions. The model is basic on Hill [29] and Ibrahim and Suparno [16]. In this paper, the model is modified into four delays in payment policy and reducing carbon emission. This section also contains an explanation of the list of notations. 


\subsection{Notations}

The notation used in the model is presented below:

$i \quad$ : Supply chain player (s: supplier, $m$ : manufacturer, $d$ : distributor)

$j \quad$ : Type of inventory ( $w$ : raw material, f: finished goods)

$A_{i, j} \quad:$ Setup/order cost incurred by player-i to the item-j

$C_{i, j} \quad:$ Production/purchases cost per item issued by player-i for the item-j

$h_{i, j} \quad$ : Financial holding cost per item issued by player-i for the item-j

$S_{i, j} \quad$ : Physical (storage) holding cost per item issued by player-i for the item-j

$Q \quad$ : Distributor order quantity

$n_{1} \quad$ : The number of shipments of the supplier to manufacturing per manufacturing material cycle.

$n_{2} \quad$ : The number of shipments by manufacturing to the distributor per distributor cycle

$\alpha \quad$ : The number of raw materials needed to produce one finished product

$t_{i} \quad$ : The time of the delay in payments offered by player-i

$\tau_{i} \quad$ : The payment time made by player-i

$k_{i} \quad$ : Return on investment (ROI) for player-i

$P \quad$ : The annual production rate of manufacture

$D \quad$ : Distributor annual demand $D<P$

$T \quad$ : Common cycle length $=\frac{n_{2} Q}{D}$

$T_{S} \quad:$ Supplier cycle length $=\frac{n_{2} Q}{P}$

$T_{w} \quad$ : Manufacture raw material cycle length $=\frac{n_{2} Q}{n_{1} P}$

$T_{m} \quad$ : Manufacture finish product cycle length $=\frac{n_{2} Q}{D}$

$T_{d} \quad:$ Distributor cycle length $=\frac{Q}{D}$

$A_{0} \quad$ : Transport Cost at the start of an order point

$T_{e} \quad$ : Transport emission tax

$T_{c i} \quad$ : Emission tax rate

$T_{\text {cap }}:$ Truck capability

$n_{t} \quad$ : Number of a truck per shipment $\left(Q / T_{\text {cap }}\right)$

$E_{m} \quad$ : Manufacturing Emission $E_{m}=a P^{2}-b P+c,(a, b, c$ are parameters $)$

$S C \quad$ : Total annual cost of supplier

$M C \quad$ : Total annual cost of manufacturer

$D C$ : Total annual cost of a distributor

TSC : Total annual cost of supply chain system

\subsection{Assumptions}

This study used several assumptions to limit the scope of the model, given below: 1). One type of product, one supplier, one manufacturer, and one distributor; 2). Demand is deterministic based on distributor information; 3). The supplier's production level is higher than the manufacturer's raw material demand; 4). The manufacturer's production level is higher than distributor demand; 5). Holding cost components are divided into financial holding cost and physical holding cost; 6 ). Supplier and manufacturer offer delay in payment; 7). The period of delay in payment and order quantity becomes the decision variable; 8). Both manufacture and distributor invest their vendor owes in risk-free investments during the allowed period; 9). Both manufacture and distributor pay debt with one payment; 10). An unlimited number of trucks; and 11). Routes are not considered. 


\subsection{Conceptual Model}

In this study, formulation of mathematical models considering the length of the cycle, where overall cycle length is $T=\frac{n_{2} Q}{D}$. The mathematical model in this study is the extension of the Ibrahim and Suparno [16] model. They do not consider carbon emission costs. The players in the supply chain system are suppliers, manufacturers, and distributors. Coordination among the players does with the delay in consideration of the payment. In this study, the previous mathematical model was modified to determine the effect of delay in payment on reducing gas emissions. Fig. 1 shows the integration model between suppliers with manufacturer and producers with the distributor.

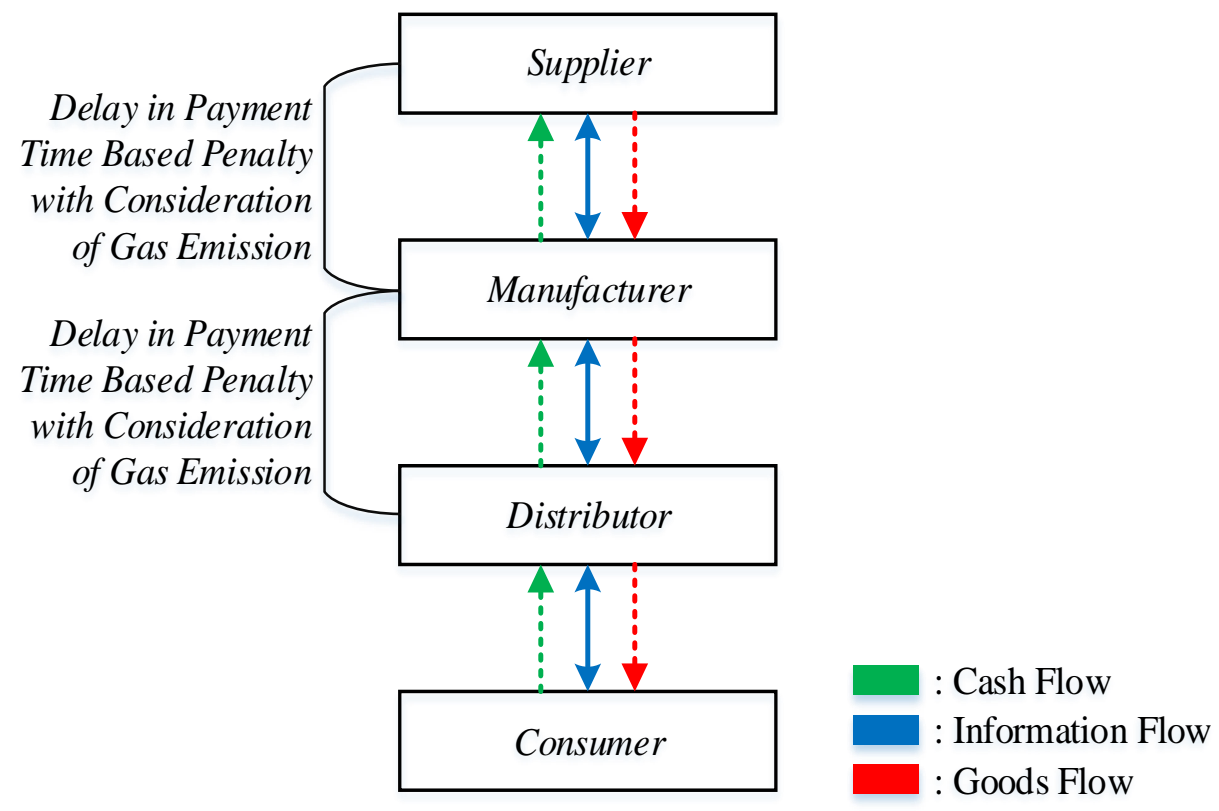

Fig. 1. Conceptual Model

Mathematical models were developed into several case scenarios. Every case is a combination of subcase on echelon 1 (supplier-manufacturer) and echelon 2 (manufacturer-distributor). Table 1 shows the scheme of four case scenarios used in this study. Respectively there are two sub-cases in the first echelon and second echelon. Subcase, one at Echelon 1 described the supplier provide a delay in the payment period for time to complete the payment without interest costs. The manufacturer made payments right at the end of the delay in the payment period provided by the supplier. In this sub-case, the manufacturer not offered compensation for suppliers because making payments does not exceed the limit of the delay in the cash.

While in the second sub-echelon 1 , it showed delays in the payment of the manufacturer. However, the manufacturer made the payment and not causes a delay in the period or before receiving the next shipment. In this sub-case, the manufacturer must compensate the supplier for making payments during the delay period provided by the supplier. There were two subcases on the echelon. It same as the two subcases on echelon 1. The difference was that it applied to the relationship between manufacturer and distributor. This conceptual model is carried out in the previous model and explained in the next section. 
Table 1. Case scenario

\begin{tabular}{ccc} 
Echelon 1 & Echelon 2 & Case Name \\
$0 \leq t_{s}=\tau_{m} \leq \frac{n_{2} Q}{P n_{1}}$ & $0 \leq t_{m}=\tau_{d} \leq \frac{Q}{D}$ & 1.1 \\
\cline { 2 - 3 } & $0 \leq t_{m}<\tau_{d} \leq \frac{Q}{D}$ & 1.2 \\
$0 \leq t_{s}<\tau_{m} \leq \frac{n_{2} Q}{P n_{1}}$ & $0 \leq t_{m}=\tau_{d} \leq \frac{Q}{D}$ & 2.1 \\
\cline { 2 - 3 } & $0 \leq t_{m}<\tau_{d} \leq \frac{Q}{D}$ & 2.2 \\
\hline
\end{tabular}

\subsection{Mathematical Model}

In this study, a mathematical model was developed to coordinate players in an integrated supply chain system by reducing carbon emissions. Mathematical models are formulated by considering general cycle length $T=\frac{\mathrm{n}_{2} \mathrm{Q}}{\mathrm{D}}$.

Model for Case 1.1: $0 \leq t_{s}=\tau_{m} \leq \frac{n_{2} Q}{P n_{1}} ; 0 \leq t_{m}=\tau_{d} \leq \frac{Q}{D}$

For case 1.1, supplier costs, Manufacturer Costs (Raw Materials), Manufacturer Costs (Finish Goods), and Distributor Costs are presented in equations (1), (2), (3), and (4).

$$
\begin{gathered}
\psi_{s}^{1.1}=A_{s, f}+C_{s, f} \alpha n_{2} Q+\frac{n_{1}\left(n_{1}-1\right)}{2}\left(h_{s, f}+S_{s, f}\right)\left(\frac{\alpha n_{2}{ }^{2} Q^{2}}{P n_{1}{ }^{2}}\right)+h_{s, f} \tau_{m} \alpha n_{2} Q \\
+\left(C_{m, w}-C_{s, f}\right) \alpha n_{2} Q e^{k_{s} t_{s}}+E_{m} D T_{c i}
\end{gathered}
$$

$$
\begin{aligned}
\psi_{m, w}^{1.1}=n_{1} A_{m, w} & +C_{m, w} \alpha n_{2} Q+h_{m, w} \frac{\alpha^{2} n_{2}{ }^{2} Q^{2}}{2 \alpha P n_{1}}-h_{m, w} \alpha n_{2} Q t_{s}+h_{m, w} \frac{n_{1} \alpha P t_{s}{ }^{2}}{2}+S_{m, w} \frac{\alpha n_{2}{ }^{2} Q^{2}}{2 P n_{1}} \\
& -C_{m, w} \alpha n_{2} Q e^{k_{m} \tau_{m}}
\end{aligned}
$$

$$
\begin{aligned}
\psi_{m, f}^{1.1}=A_{m, f}+ & C_{m, f} n_{2} Q+\left(h_{m, f}+S_{m, f}\right)\left(\frac{n_{2} Q^{2}\left(2 D+(P-D) n_{2}-P\right)}{2 D P}\right)+h_{m, f} \tau_{d} n_{2} Q \\
& +\left(C_{d, f}-C_{m, f}\right) n_{2} Q e^{k_{m} t_{m}}+E_{m} D T_{c i}
\end{aligned}
$$

$$
\begin{aligned}
\psi_{d, f}^{1.1}=n_{2} A_{d, f}+ & C_{d, f} n_{2} Q+n_{2} h_{d, f} \frac{\left(Q-D t_{m}\right)^{2}}{2 D}+\frac{S_{d, f} n_{2} Q^{2}}{2 D}-n_{2} Q C_{d, f}\left(1-e^{k_{d} t_{m}}\right)+n_{t} \frac{D A_{0}}{Q} \\
& +n_{t} \frac{D T_{e}}{Q}
\end{aligned}
$$

The total cost of every cycle of the system is obtained by totalizing equations (1), (2), (3), and (4). The total annual cost is produced by The total cost of every period that divides the length of the general cycle. Formula The total annual cost Case 1.1 is shown in equation (5). 


$$
\begin{aligned}
\psi_{S C}^{1.1}=\frac{A_{s, f} D}{n_{2} Q}+ & C_{s, f} \alpha D+\frac{n_{1}\left(n_{1}-1\right)}{2}\left(h_{s, f}+S_{s, f}\right) \frac{\alpha n_{2} Q D}{P n_{1}{ }^{2}}+h_{s, f} \tau_{m} \alpha D+\left(C_{m, w}-C_{s, f}\right) e^{k_{s} t_{s} \alpha D} \\
& +\frac{E_{m} D T_{c i} D}{n_{2} Q}+\frac{n_{1} A_{m, w} D}{n_{2} Q}+\frac{C_{m, w} \alpha n_{2} Q D}{n_{2} Q}+\frac{h_{m, w} \alpha^{2} n_{2}{ }^{2} Q^{2} D}{2 \alpha P n_{1} n_{2} Q}-\frac{h_{m, w} \alpha n_{2} Q t_{s} D}{n_{2} Q} \\
& +\frac{h_{m, w} n_{1} \alpha P t_{s}{ }^{2} D}{2 n_{2} Q}+\frac{S_{m, w} \alpha n_{2}{ }^{2} Q^{2} D}{2 P n_{1} n_{2} Q}-\frac{C_{m, w} \alpha n_{2} Q e^{k_{m} \tau_{m}} D}{n_{2} Q}+\frac{A_{m, f} D}{n_{2} Q}+C_{m, f} D \\
& +\left(h_{m, f}+S_{m, f}\right)\left(\frac{Q\left(2 D+(P-D) n_{2}-P\right)}{2 P}\right)+h_{m, f} \tau_{d} D+\left(C_{d, f}-C_{m, f}\right) e^{k_{m} t_{m} D} \\
& +\frac{E_{m} D T_{c i} D}{n_{2} Q}+\frac{A_{d, f} D}{Q}+C_{d, f} D+\frac{h_{d, f}\left(Q-D t_{m}\right)^{2}}{2 Q}+\frac{S_{d, f} Q}{2}-C_{d, f} D\left(1-e^{k_{d} t_{m}}\right) \\
& +n_{t} A_{0} n_{2}+n_{t} T_{e} n_{2}
\end{aligned}
$$

Model for Case 1.2: $0 \leq t_{s}=\tau_{m} \leq \frac{n_{2} Q}{P n_{1}}$ dan $0 \leq t_{m}<\tau_{d} \leq \frac{Q}{D}$

For model case 1.2, Supplier Costs 1.1 is $\psi_{s}^{1.2}=\psi_{s}^{1.1}$, Manufacturer Costs (Raw Materials) $1.1 \psi_{m, w}^{1.2}=\psi_{m, w}^{1.1}$. Formula The total annual cost case 1.2 is shown in equation (6).

$$
\begin{aligned}
\psi_{S C}^{1.2}=\frac{A_{s, f} D}{n_{2} Q}+ & C_{s, f} \alpha D+\frac{n_{1}\left(n_{1}-1\right)}{2}\left(h_{s, f}+S_{s, f}\right) \frac{\alpha n_{2} Q D}{P n_{1}{ }^{2}}+h_{s, f} \tau_{m} \alpha D+\left(C_{m, w}-C_{s, f}\right) e^{k_{s} t_{s}} \alpha D \\
& +\frac{E_{m} D T_{c i} D}{n_{2} Q}+\frac{n_{1} A_{m, w} D}{n_{2} Q}+\frac{C_{m, w} \alpha n_{2} Q D}{n_{2} Q}+\frac{h_{m, w} \alpha^{2} n_{2}{ }^{2} Q^{2} D}{2 \alpha P n_{1} n_{2} Q}-\frac{h_{m, w} \alpha n_{2} Q t_{s} D}{n_{2} Q} \\
& +\frac{h_{m, w} n_{1} \alpha P t_{s}{ }^{2} D}{2 n_{2} Q}+\frac{S_{m, w} \alpha n_{2}{ }^{2} Q^{2} D}{2 P n_{1} n_{2} Q}-\frac{C_{m, w} \alpha n_{2} Q e^{k_{m} \tau_{m}} D}{n_{2} Q}+\frac{A_{m, f} D}{n_{2} Q}+C_{m, f} D \\
& +\left(h_{m, f}+S_{m, f}\right)\left(\frac{Q\left(2 D+(P-D) n_{2}-P\right)}{2 P}\right)+h_{m, f} \tau_{d} D+\left(C_{d, f}-C_{m, f}\right) e^{k_{m} t_{m} D} \\
& -C_{d, f} e^{k_{m}\left(\tau_{d}-t_{m}\right)} D+\frac{E_{m} D T_{c i} D}{n_{2} Q}+\frac{A_{d, f} D}{Q}+C_{d, f} D+\frac{h_{d, f}\left(Q-D t_{m}\right)^{2}}{2 Q}+\frac{S_{d, f} Q}{2} \\
& +C_{d, f} e^{k_{m}\left(\tau_{d}-t_{m}\right)} D-C_{d, f} D\left(1-e^{k_{d} t_{m}}\right)+n_{t} A_{0} n_{2}+n_{t} T_{e} n_{2}
\end{aligned}
$$

Model for Case 2.1: $0 \leq t_{s}<\tau_{m} \leq \frac{n_{2} Q}{P n_{1}}$ dan $0 \leq t_{m}=\tau_{d} \leq \frac{Q}{D}$

For model case 2.1, Manufacturer Costs (Finish Goods) is $\psi_{m, f}^{2.1}=\psi_{m, f}^{1.1}$, Distributor Cost $\psi_{d, f}^{2.1}=\psi_{d, f}^{1.1}$. Formula The total annual cost case 2.1 is shown in equation (7).

$$
\begin{aligned}
\psi_{S C}^{2.1}=\frac{A_{s, f} D}{n_{2} Q}+ & C_{s, f} \alpha D+\frac{n_{1}\left(n_{1}-1\right)}{2}\left(h_{s, f}+S_{s, f}\right) \frac{\alpha n_{2} Q D}{P n_{1}{ }^{2}}+h_{s, f} \tau_{m} \alpha D+\left(C_{m, w}-C_{s, f}\right) e^{k_{s} t_{s}} \alpha D \\
& -C_{m, w} e^{k_{s}\left(\tau_{m}-t_{s}\right)} \alpha D+\frac{E_{m} D T_{c i} D}{n_{2} Q}+\frac{n_{1} A_{m, w} D}{n_{2} Q}+\frac{C_{m, w} \alpha n_{2} Q D}{n_{2} Q}+\frac{h_{m, w} \alpha^{2} n_{2}{ }^{2} Q}{2 \alpha P n_{1} n_{2} Q} \\
& -\frac{h_{m, w} \alpha n_{2} Q t_{s} D}{n_{2} Q}+\frac{h_{m, w} n_{1} \alpha P t_{s}{ }^{2} D}{2 n_{2} Q}+\frac{S_{m, w} \alpha n_{2}{ }^{2} Q^{2} D}{2 P n_{1} n_{2} Q}+\frac{C_{m, w} \alpha n_{2} Q e^{k_{s}\left(\tau_{m}-t_{s}\right)} D}{n_{2} Q} \\
& -\frac{C_{m, w} \alpha n_{2} Q e^{k_{m} \tau_{m}} D}{n_{2} Q}+\frac{A_{m, f} D}{n_{2} Q}+C_{m, f} D \\
& +\left(h_{m, f}+S_{m, f}\right)\left(\frac{Q\left(2 D+(P-D) n_{2}-P\right)}{2 P}\right)+h_{m, f} \tau_{d} D+\left(C_{d, f}-C_{m, f}\right) e^{k_{m} t_{m} D} \\
& +\frac{E_{m} D T_{c i} D}{n_{2} Q}+\frac{A_{d, f} D}{Q}+C_{d, f} D+\frac{h_{d, f}\left(Q-D t_{m}\right)^{2}}{2 Q}+\frac{S_{d, f} Q}{2}-C_{d, f} D\left(1-e^{k_{d} t_{m}}\right) \\
& +n_{t} A_{0} n_{2}+n_{t} T_{e} n_{2}
\end{aligned}
$$


Model for Case 2.2: $0 \leq t_{s}<\tau_{m} \leq \frac{n_{2} Q}{P n_{1}}$ dan $0 \leq t_{m}<\tau_{d} \leq \frac{Q}{D}$

For model case 2.1, Supplier Costs is $\psi_{s}^{2.2}=\psi_{s}^{2.1}$, Manufacturer Costs (Raw Materials) $\psi_{m, w}^{2.2}=\psi_{m, w}^{2.1}$, Manufacturer Costs (Finish Goods) $\psi_{m, f}^{2.2}=\psi_{m, f}^{1.2}$, Distributor Cost $\psi_{d, f}^{2.2}=\psi_{d, f}^{1.2}$. Formula The total annual cost case 2.2 is shown in equation (8).

$$
\begin{aligned}
\psi_{S C}^{2.2}=\frac{A_{s, f} D}{n_{2} Q}+ & C_{s, f} \alpha D+\frac{n_{1}\left(n_{1}-1\right)}{2}\left(h_{s, f}+S_{s, f}\right) \frac{\alpha n_{2} Q D}{P n_{1}{ }^{2}}+h_{s, f} \tau_{m} \alpha D+\left(C_{m, w}-C_{s, f}\right) e^{k_{s} t_{s}} \alpha D \\
& -C_{m, w} e^{k_{s}\left(\tau_{m}-t_{s}\right)} \alpha D+\frac{E_{m} D T_{c i} D}{n_{2} Q}+\frac{n_{1} A_{m, w} D}{n_{2} Q}+\frac{C_{m, w} \alpha n_{2} Q D}{n_{2} Q}+\frac{h_{m, w} \alpha^{2} n_{2}{ }^{2} Q^{2} D}{2 \alpha P n_{1} n_{2} Q} \\
& -\frac{h_{m, w} \alpha n_{2} Q t_{s} D}{n_{2} Q}+\frac{h_{m, w} n_{1} \alpha P t_{s}{ }^{2} D}{2 n_{2} Q}+\frac{S_{m, w} \alpha n_{2}{ }^{2} Q^{2} D}{2 P n_{1} n_{2} Q}+\frac{C_{m, w} \alpha n_{2} Q e^{k_{s}\left(\tau_{m}-t_{s}\right)} D}{n_{2} Q} \\
& -\frac{C_{m, w} \alpha n_{2} Q e^{k_{m} \tau_{m}} D}{n_{2} Q}+\frac{A_{m, f} D}{n_{2} Q}+C_{m, f} D \\
& +\left(h_{m, f}+S_{m, f}\right)\left(\frac{Q\left(2 D+(P-D) n_{2}-P\right)}{2 P}\right)+h_{m, f} \tau_{d} D+\left(C_{d, f}-C_{m, f}\right) e^{k_{m} t_{m} D} \\
& -C_{d, f} e^{k_{m}\left(\tau_{d}-t_{m}\right)} D+\frac{E_{m} D T_{c i} D}{n_{2} Q}+\frac{A_{d, f} D}{Q}+C_{d, f} D+\frac{h_{d, f}\left(Q-D t_{m}\right)^{2}}{2 Q}+\frac{S_{d, f} Q}{2} \\
& -C_{d, f} D\left(1-e^{k_{d} t_{m}}\right)+n_{t} A_{0} n_{2}+n_{t} T_{e} n_{2}
\end{aligned}
$$

\subsection{Numerical experiment procedure}

In this section, numerical experiments are conducted to compare the four scenarios that have been developed in Section 2. Besides, numerical examples represent the model's behavior according to the four scenarios and examine the impact of late payments. Parameter values used in this example adapted from previous studies conducted by Aljazzar, et al. [14], where: $D=1000, P=3200, \alpha=1, A_{s, f}=441, A_{m, w}=206, A_{m, f}=175$, $A_{d, f}=384, C_{s, f}=20, C_{m, w}=30, C_{m, f}=50, C_{d, f}=70, h_{s, j}=3, h_{m, w}=3, h_{m, f}=12, h_{d, f}=$ 13.3, $S_{s, f}=3, S_{m, w}=7.5, S_{m, f}=9, S_{d, f}=7.7, n_{1}=1, n_{2}=2, k_{s}=0.01, k_{m}=0.08, k_{d}=0.04$, $e=0.10, T_{c i}=20, n_{t}=7, A_{0}=10, T_{e}=20, E_{m}=0.632, T_{\text {cap }}=80$.

We used the values of the input parameter already explain before to get the optimal solution. In this paper, Solver on Excel Software was used to search for the optimal solution of the model. The solver was chosen because simple and has a relatively short computing time. Furthermore, Maple software was used to validate the calculation.

\section{Results and Discussion}

\subsection{Numerical experiment results}

This section shows the result of a numerical example. The result is done to compare the four scenarios that have been explained in Section 2. Moreover, the numerical example was also arranged with another scenario that does not use delay in payment. It is presented in scenario (0.0). Through a series of formulations and validations, the result of optimum values $Q, t_{s}, \tau_{m}, t_{m}$, and $\tau_{d}$ under four differences of scenarios are shown in Table 2 .

Furthermore, sensitivity analysis is carried out for some important parameters. Distributor Return on Investment (ROI), emission tax rate when the delay in payment allowed, and not allowed. Very interesting to pay attention to the ROI of the distributor. Based on previous studies conducted by [14,16,21,25], Distributor ROI is always discussed 
because of its impact on the supply chain system. Therefore, in this experiment, the author experimented by varying the distributor ROI into several different percentages. Table 3 shows the results of sensitivity analysis by varying distributor ROI.

Table 2. Numerical experiment result

\begin{tabular}{cccccc}
\hline Scenario & 0.0 & 1.1 & $1.2^{*}$ & 2.1 & 2.2 \\
Name & 542 & 491 & 800 & 599 & 800 \\
$\mathrm{Q}$ & 0.00 & 0.01 & 0.01 & 0.01 & 0.01 \\
$t_{s}$ & 0.00 & 0.01 & 0.01 & 0.02 & 0.02 \\
$\tau_{m}$ & 0.00 & 0.40 & 0.64 & 0.49 & 0.64 \\
$t_{m}$ & 0.00 & 0.40 & 0.65 & 0.49 & 0.65 \\
$\tau_{d}$ & 42,083 & 43,358 & 38,203 & 10,995 & 8,240 \\
$\mathrm{SC}$ & 90,452 & 93,223 & 24,900 & 125,410 & 54,947 \\
$\mathrm{MC}$ & 76,813 & 70,642 & 140,343 & 70,490 & 140,344 \\
$\mathrm{DC}$ & 209,348 & 207,224 & 203,446 & 206,894 & 203,531 \\
$\mathrm{TSC}$ & $23,738.39$ & $26,190.41$ & $16,175.03$ & $21,523.9$ & $16,175.01$ \\
$\mathrm{EC}$ & & & & & \\
\hline
\end{tabular}

Table 3. Effect of varying distributor ROI

\begin{tabular}{ccccc}
\hline$k_{d}$ & $\mathrm{Q}$ & $t_{m}$ & $\tau_{d}$ & $\mathrm{EC}$ \\
\hline 0.01 & 683 & 0.33 & 0.34 & $18,908.47$ \\
0.02 & 782 & 0.46 & 0.47 & $16,547.43$ \\
0.04 & 800 & 0.64 & 0.65 & $16,175.03$ \\
0.06 & 867 & 0.85 & 0.86 & $14,962.43$ \\
0.08 & 880 & 0.87 & 0.88 & $14,738.64$ \\
0.1 & 960 & 0.95 & 0.96 & $13,541.68$ \\
\hline
\end{tabular}

The emission tax rate is considered one of the critical parameters, and variations are made on these parameters. Several previous studies that discussed the low carbon supply chain always examined emission tax rates or emission rates. According to Bai, et al. [30], policies such as cap-and-trade are effective methods for reducing carbon emissions. Indeed, such policies consider tax rates or emission rates. Nevertheless, the role of the government as the policy provider is vital here; one of them is the cap-and-trade policy $[5,30,31]$. Table 4 shows the results of sensitivity analysis by varying emission tax in two different conditions.

Table 4. The Effect of varying emission tax rate when the delay in payment allowed and not allowed

\begin{tabular}{ccccccc|ccccccc}
\hline \multicolumn{1}{c}{ Delay in Payment Allowed } & \multicolumn{4}{c}{ Delay in Payment not Allowed } \\
\hline$T_{C i}$ & $\mathrm{Q}$ & $t_{s}$ & $\tau_{m}$ & $t_{m}$ & $\tau_{d}$ & $\mathrm{EC}$ & $T_{C i}$ & $\mathrm{Q}$ & $t_{s}$ & $\tau_{m}$ & $t_{m}$ & $\tau_{d}$ & $\mathrm{EC}$ \\
5 & 448 & 0.01 & 0.01 & 0.37 & 0.38 & $7,464.31$ & 5 & 404 & 0.00 & 0.00 & 0.00 & 0.01 & $8,275.77$ \\
10 & 560 & 0.01 & 0.01 & 0.46 & 0.47 & $11,660.72$ & 10 & 542 & 0.00 & 0.00 & 0.00 & 0.01 & $12,063.16$ \\
15 & 717 & 0.01 & 0.01 & 0.58 & 0.59 & $13,588.19$ & 15 & 651 & 0.00 & 0.00 & 0.00 & 0.01 & $14,988.19$ \\
20 & 800 & 0.01 & 0.01 & 0.64 & 0.65 & $16,175.01$ & 20 & 744 & 0.00 & 0.00 & 0.00 & 0.01 & $17,396.06$ \\
25 & 880 & 0.01 & 0.01 & 0.70 & 0.71 & $18,329.57$ & 25 & 827 & 0.00 & 0.00 & 0.00 & 0.01 & $19,511.08$ \\
30 & 960 & 0.01 & 0.01 & 0.76 & 0.77 & $20,125.00$ & 30 & 902 & 0.00 & 0.00 & 0.00 & 0.01 & $21,419.24$ \\
\hline \multicolumn{4}{c}{ Total Emission Cost } & & $87,342.80$ & \multicolumn{4}{c}{ Total Emission Cost } & & $93,653.50$ \\
\hline
\end{tabular}




\subsection{Analysis \& Discussion}

Table 2 shows that all supplier scenarios always present short payment delays. The minimum of total supply chain costs occurs when using scenarios (1.2). The findings state that the short period delay in payment from suppliers occurs due to a small percentage of supplier ROI. Moreover, it becomes longer when the ROI increases. From this numerical experiment, ROI parameters hugely affect the player's income. It refers to a period of late payment from the producer that is longer than the supplier and proportional to the higher ROI manufacturer.

On the other hand, the minimum emission cost also occurs in a scenario with a delay in payment. Decreasing emission costs arise due to an increase in quantity shipment. This decrease occurred due to shipping in large volumes, so vehicle travel more efficient.

Table 3 shows the effect of varying distributor ROI. According to sensitivity analysis, the higher the distributor's ROI, the higher the payment period delay. Besides, the longer the manufacturer delays payment to the distributor, the distributor's order is higher. When the ROP of the distributor is 0.01 , the time of the manufacturer's payment delay is 0.34 units, and the distributor's orders are 683 units. On the other hand, the manufacturer gives a longer delay in payment as big as 0.65 units when the distributor ROP 0.04. Hence, the order quantity increased to 800 units. The higher-order amount produces a smaller emission cost. These cost emissions occur due to various events, but the transportation cost represents emissions cost in this research.

Table 4 presents the result of the numerical experiment when varying emission tax rates. The result shows a relation between the emission tax rate with a delay in the payment period and order quantity. When the emission tax rises, the delay in the manufacturer's payment period increases indirectly. Besides, the order quantity indirectly increases along with the rising delay in the manufacturer's payment period. It automatically occurs and proves the model successfully integrates the supply chain system under study. Players in the supply chain system try to reduce emissions costs by coordinating through delays in payment when the emissions tax increase. Therefore, manufacturers provide a longer delay in the payment period, and distributors increase their order quantity to minimize emissions costs.

According to numerical experiments, low emission costs occur when the delay of the payment is permitted. It can be concluded, a delay in payment becomes a coordination medium in an integrated supply chain system to reduce gas emissions. The delay in payment reduces gas emissions because the delay in payment provided by the supplier makes the buyer buy in larger quantities. Besides, the order quantity is also strongly influenced by distributor ROI. In Table 3, the higher the distributor ROI produces, the higher the order quantity as well. Higher-order supplies can optimize shipping from suppliers to buyers, thereby reducing gas emissions. With this mechanism, both parties benefit from each other.

\section{Conclusion}

The model in this study successfully integrates the multi-echelon supply chain with late payments as media coordination. Coordination with delay in payment has succeeded in reducing the total supply chain costs, especially carbon emissions. Lower emission costs show successful coordination in the supply chain. The total cost of the supply chain system is lower when given a period of late payment. The period of late payment provided by the supplier makes customers purchase in larger quantities. Moreover, the order quantity is 
strongly affected by distributor ROI. The higher distributor ROI produces a higher order quantity as well. Higher-order supplies can optimize shipping from suppliers to buyers by reducing gas emissions. In this study, the cost of carbon emissions is obtained by considering transportation costs and distribution. Further research can be developed by considering the expenses that occur during production and other business processes.

\section{Acknowledgment}

This research is supported and financed by the Ministry of Research, Technology, and Higher Education of the Republic of Indonesia under the PDP scheme.

\section{References}

[1] A. A. King and M. J. Lenox, "Industry self-regulation without sanctions: The chemical industry's responsible care program," Academy of management journal, vol. 43, pp. 698-716, 2000. https://doi.org/10.5465/1556362.

[2] M. Djunaidi, M. A. A. Sholeh, and N. M. Mufiid, "Identifikasi Faktor Penerapan Green Supply Chain Management Pada Industri Furniture Kayu," 2018, vol. 19, pp.1-10, Jurnal Teknik Industri, 2018. https://doi.org/10.22219/JTIUMM.Vol19.No1.1-10.

[3] D. Zissis, G. K. D. Saharidis, E. Aktas, and G. Ioannou, "Emission reduction via supply chain coordination," Transportation Research Part D: Transport and Environment, vol. 62, pp. 36-46, 2018. https://doi.org/10.1016/j.trd.2018.01.014.

[4] H. Peng, T. Pang, and J. Cong, "Coordination contracts for a supply chain with yield uncertainty and low-carbon preference," Journal of Cleaner Production, vol. 205, pp. 291-302, 2018. https://doi.org/10.1016/j.jclepro.2018.09.038.

[5] L. Xu, C. Wang, and J. Zhao, "Decision and coordination in the dual-channel supply chain considering cap-and-trade regulation," Journal of Cleaner Production, vol. 197, pp. 551-561, 2018. https://doi.org/10.1016/j.jclepro.2018.06.209.

[6] Q. Bai, X. Xu, J. Xu, and D. Wang, "Coordinating a supply chain for deteriorating items with multi-factor-dependent demand over a finite planning horizon," Applied Mathematical Modelling, vol. 40, pp. 9342-9361, 2016. https://doi.org/10.1016/j.apm.2016.06.021.

[7] P. Liu, "Pricing policies and coordination of low-carbon supply chain considering targeted advertisement and carbon emission reduction costs in the big data environment," Journal of Cleaner Production, vol. 210, pp. 343-357, 2019. https://doi.org/10.1016/j.jclepro.2018.10.328.

[8] Q. Bai, J. Xu, and Y. Zhang, "Emission reduction decision and coordination of a make-to-order supply chain with two products under cap-and-trade regulation," Computers \& Industrial Engineering, vol. 119, pp. 131-145, 2018. https://doi.org/10.1016/j.cie.2018.03.032.

[9] S. K. Zahran, M. Y. Jaber, and S. Zanoni, "The consignment stock case for a vendor and a buyer with delay-in-payments," Computers \& Industrial Engineering, vol. 98, pp. 333-349, 2016. https://doi.org/10.1016/j.cie.2016.06.010.

[10] S. M. Aljazzar, A. Gurtu, and M. Y. Jaber, "Delay-in-payments - A strategy to reduce carbon emissions from supply chains," Journal of Cleaner Production, vol. 170, pp. 636-644, 2018. https://doi.org/10.1016/j.jclepro.2017.08.177.

[11] D. Waters, Inventory Control and Management: Wiley, 1992. 
[12] S. Seuring, "Integrated chain management and supply chain management comparative analysis and illustrative cases," Journal of Cleaner Production, vol. 12, pp. 1059-1071, 2004. http://dx.doi.org/10.1016/j.jclepro.2004.02.006.

[13] H. Stadtler, "Supply chain management and advanced planning-basics, overview and challenges," European Journal of Operational Research, vol. 163, pp. 575-588, 2005. http://dx.doi.org/10.1016/j.ejor.2004.03.001.

[14] S. M. Aljazzar, M. Y. Jaber, and L. Moussawi-Haidar, "Coordination of a three-level supply chain (supplier-manufacturer-retailer) with permissible delay in payments," Applied Mathematical Modelling, vol. 40, pp. 9594-9614, 2016. https://doi.org/10.1016/j.apm.2016.06.006.

[15] J. Heydari, M. Rastegar, and C. H. Glock, "A two-level delay in payments contract for supply chain coordination: The case of credit-dependent demand," International Journal of Production Economics, vol. 191, pp. 26-36, 2017. https://doi.org/10.1016/j.ijpe.2017.05.004.

[16] M. F. Ibrahim and Suparno, "Integration of three echelon supply chain (suppliermanufacturer-distributor-drop shipper) with permissible delay in payment and penalty contract," in IOP Conference Series: Materials Science and Engineering, 2018, p. 012027. https://doi.org/10.1088/1757-899X/337/1/012027.

[17] C. H. Glock, "The joint economic lot size problem: A review," International Journal of Production Economics, vol. 135, pp. 671-686, 2012. http://dx.doi.org/10.1016/j.ijpe.2011.10.026.

[18] J. Heydari, P. Zaabi-Ahmadi, and T.-M. Choi, "Coordinating supply chains with stochastic demand by crashing lead times," Computers \& Operations Research, vol. 100, pp. 394-403, 2018. https://doi.org/10.1016/j.cor.2016.10.009.

[19] A. Sainathan and H. Groenevelt, "Vendor managed inventory contracts coordinating the supply chain while looking from the vendor's perspective," European Journal of Operational Research, vol. 272, pp. 249-260, 2019. https://doi.org/10.1016/j.ejor.2018.06.028.

[20] M. Zamarripa, K. Hjaila, J. Silvente, and A. Espuña, "Tactical management for coordinated supply chains," Computers \& Chemical Engineering, vol. 66, pp. 110123, 2014. https://doi.org/10.1016/j.compchemeng.2014.02.006.

[21] M. F. Ibrahim, "Integration Dual Channel Supply Chain with Permissible Delay in Payment \& Delay of Online Product Launch Considerations," in 2018 International Conference on Computing, Engineering, and Design (ICCED), 2018, pp. 181-186. https://doi.org/10.1109/ICCED.2018.00043.

[22] H. Reefke and D. Sundaram, "Key themes and research opportunities in sustainable supply chain management - identification and evaluation," Omega, vol. 66, pp. 195-211, 2017. https://doi.org/10.1016/j.omega.2016.02.003.

[23] A. A. King and M. J. Lenox, "Industry Self-Regulation without Sanctions: The Chemical Industry's Responsible Care Program," The Academy of Management Journal, vol. 43, pp. 698-716, 2000. https://doi.org/10.2307/1556362.

[24] J. Sarkis and Y. Dou, Green Supply Chain Management: A Concise Introduction: Taylor \& Francis, 2017. https://doi.org/10.4324/9781315233000.

[25] M. Y. Jaber and I. H. Osman, "Coordinating a two-level supply chain with delay in payments and profit sharing," Computers \& Industrial Engineering, vol. 50, pp. 385-400, 2006. https://doi.org/10.1016/j.cie.2005.08.004.

[26] M. F. Ibrahim, "Integrated Supply Chain Contract Model With Drop-Shipper Players," 2018, vol. 19, pp. 58-72, Jurnal Teknik Industri, 2018. https://doi.org/10.22219/JTIUMM.Vol19.No1.58-72. 
[27] K.-J. Chung, S. K. Goyal, and Y.-F. Huang, "The optimal inventory policies under permissible delay in payments depending on the ordering quantity," International Journal of Production Economics, vol. 95, pp. 203-213, 2005. https://doi.org/10.1016/j.ijpe.2003.12.006.

[28] F. Hu and D. Liu, "Optimal replenishment policy for the EPQ model with permissible delay in payments and allowable shortages," Applied Mathematical Modelling, vol. 34, pp. 3108-3117, 2010. https://oi.org/10.1016/j.apm.2010.01.016.

[29] R. M. Hill, "The single-vendor single-buyer integrated production-inventory model with a generalised policy," European Journal of Operational Research, vol. 97, pp. 493-499, 1997. https://doi.org/10.1016/S0377-2217(96)00267-6.

[30] Q. Bai, Y. Gong, M. Jin, and X. Xu, "Effects of carbon emission reduction on supply chain coordination with vendor-managed deteriorating product inventory," International Journal of Production Economics, vol. 208, pp. 83-99, 2019. https://doi.org/10.1016/j.ijpe.2018.11.008.

[31] C. Waltho, S. Elhedhli, and F. Gzara, "Green supply chain network design: A review focused on policy adoption and emission quantification," International Journal of Production Economics, vol. 208, pp. 305-318, 2019. https://doi.org/10.1016/j.ijpe.2018.12.003. 